\title{
An Investigation of the Effect of Different Levels of Nitrogen Fertilizers on Yield of Rice Varieties in Tons
}

\author{
Ayobami I. Okegbade ${ }^{1}$, Taiwo J. Adejumo ${ }^{1, *}$, Dare O. Omonijo ${ }^{2,3}$, Olusola B. Okunlola ${ }^{4}$ \\ ${ }^{1}$ Department of Statistics, Ladoke Akintola University of Technology, Ogbomoso Oyo State, Nigeria \\ ${ }^{2}$ Department of Student Industrial Work Experience Scheme, Covenant University, Ota, Nigeria \\ ${ }^{3}$ Department of Sociology, Olabisi Onabanjo University, Ago-Iwoye, Nigeria \\ ${ }^{4}$ Department of Psychology, Covenant University, Ota, Nigeria
}

Received October 19, 2020; Revised December 8, 2020; Accepted December 20, 2020

\section{Cite This Paper in the following Citation Styles}

(a): [1] Okegbade Ayobami I., Adejumo Taiwo J., Omonijo Dare O., Okunlola Olusola B. , "An Investigation of the Effect of Different Levels of Nitrogen Fertilizers on Yield of Rice Varieties in Tons," Universal Journal of Agricultural Research, Vol. 9, No. 1, pp. 13 - 21, 2021. DOI: 10.13189/ujar.2021.090103.

(b): Okegbade Ayobami I., Adejumo Taiwo J., Omonijo Dare O., Okunlola Olusola B. (2021). An Investigation of the Effect of Different Levels of Nitrogen Fertilizers on Yield of Rice Varieties in Tons. Universal Journal of Agricultural Research, 9(1), 13- 21. DOI: 10.13189/ujar.2021.090103.

Copyright@2021 by authors, all rights reserved. Authors agree that this article remains permanently open access under the terms of the Creative Commons Attribution License 4.0 International License

\begin{abstract}
This study examined the effect of various nitrogen fertilizers in kilograms: $0 \mathrm{~kg}, 30 \mathrm{~kg}, 60 \mathrm{~kg}$, and 120kg on varieties of rice: NERICA L-19; NERICA L-20; NERICA L-41; NERICA L-42; and NERICA L-60 from the department of plant physiology and crop production in the college of plant science and crop production Federal University of Agriculture Abeokuta (FUNAAB), Ogun State Nigeria. Also, to determine the appropriate fertilizer at different levels and the best variety for optimum yield of rice and to compare the treatment means for each of the crop varieties. Analysis of Variance technique was used to investigate the effect of various kilograms of nitrogen fertilizers on the yield of the five different types of NERICA rice. The findings revealed that at all the levels of nitrogen fertilizers applied, 30kg of nitrogen fertilizer gave the optimum yield. Further to that, the study discovered that different levels of the nitrogen fertilizers applied did not significantly influence the tons of NERICA rice produced, that is the yield of rice in tons is independent of kilograms of nitrogen fertilizers applied. NERICA L-42 of rice is therefore recommended to farmers to be planted with $30 \mathrm{~kg}$ of nitrogen fertilizers.
\end{abstract}

Keywords Fertilizer, Nitrogen Fertilizers, NERICA Rice, Analysis of Variance

\section{Introduction}

In many tropical countries such as Nigeria, much priority was placed on agriculture as the main stay of the economy in the time past. Then, both cash and food crops were growing extensively for the survival of individual members of family and national development. Studies have linked the present high rate of poverty and unemployment affecting many Nigerians with its abandonment and replacement for crude oil Omonijo et al. (2017).

As the value for oil keep on depreciating in recent times, the Nigeria's economy has continued to witness depression and austerity measure Omonijo et al. (2019). Consequently, the focus of well-meaning Nigerians is gradually being shifted to agriculture in order to produce food for home consumption and exportation. Studies in the past and recent times have shown the importance of food in determining human development (Omonijo et al. 2019). Such studies have linked dearth of food with social problems which include poverty, malnourishment and ill-health. As a way out, some persons have resulted in kidnapping, armed robbery, smuggling etc in order in order to survive.

Among several agricultural products, most especially food crops, planting of rice is usually considered a major occupation. The reason being that it is an annual crop and the most important staple food crop for the populace. Its consumption is enormous in many countries across the globe due to its utilization in one form or the other. In fact 
in Nigeria, it is one of the most common foods whose consumption has no bias in terms of culture, religious, ethnicity or geographical boundary. Most especially during festive periods and ceremonies it is the most common food usually prepared and served. It is usually being planted in a swampy area and land that is generally low in organic carbon and with deficiency in nitrogen has been confirmed to be suitable for its plantation. (Olaleye, et al. 2008).

Sequel to enormous advantages of varieties of New Rice for Africa (NERICA) which include; prone to drought, control of pests and diseases hence, the Federal government introduced four rain fed lowland NERICA rice which was obtained from WARDA so as to replace the existing ones and encouraged that its plantation should be done with varieties of fertilizers.

Several studies in the past have shown that adequate use of fertilizer can increase the yield and improve the quality of rice significantly (Oikeh et al. 2008; Ahmed, 2005; Awan et al. 2003). Likewise, many researchers have claimed that application of Nitrogen fertilizer to rice definitely increase height, panicle number, leaf size, spikelet number and grain yield. (Balasubramanian, 2007).

Kamara et al. (2011) carried out an analysis on the influence of nitrogen fertilization on yield and yield components of rain-fed lowland NERICA rice in the northern Guinea savanna of Nigeria. Their study evaluated the response of four rain-fed lowland New Rice for Africa (NERICA) varieties (NERICA-L-12, NERICA-L-41, NERICA-L-42 and NERICA-L-56) also known as Oryza sativa (ITA150) to nitrogen (0, 30, and $100 \mathrm{~kg} \mathrm{~N}$ ha-1). In the analysis, they found out that interactions between nitrogen and variety were not significant for all measured traits and that grain yields of the NERICAs were higher than the yield of ITA 150 (check) by 0.5 to $1.0 \mathrm{mg}$ ha- 1 . Meanwhile, when pooled across $\mathrm{N}$ rates and years, yield differences among the NERICAs were not significant and that grain yield response to nitrogen was linear. They also discovered that $100 \mathrm{~kg} \mathrm{~N}$ ha-1, grain yield was significantly increased by 3.0 and $1.5 \mathrm{mg}$ ha- 1 over the yields at 0 and 30 kg N ha-1 respectively.

Also, the investigation of Adetayo et al. (2010) was not left out. Their investigation was based on the economic importance of NERICA rice to the farmers most especially the African and Asian farmers which include widening generic variation, resistance to Africa's harsh growth conditions, short growth duration among others. They came into the conclusion that varieties of NERICA stand against drought, control pests and in fact grow faster in infertility soil compared to other varieties of rice.

In the research activities of Okello et al. (2012), they claimed that NERICA rice always yield to Nitrogen as high as $46 \mathrm{~kg} / \mathrm{ha}$ of paddy per $1 \mathrm{~kg} / \mathrm{ha}$ of Nitrogen being applied. They latter concluded that $1 \mathrm{~kg} / \mathrm{ha}$ when applied increases the yield by $8 \mathrm{~kg} / \mathrm{ha}$. Their further investigation revealed that continuous planting of NERICA rice on a particular field reduces the yield by $130 \mathrm{~kg} / \mathrm{ha}$ based on the continuous planting of the same rice on the seasonal basis. In the case of Kejiro and Sserunkuuma (2007), they affirmed that cultivation of NERICA rice particularly in the Central and Western Uganda has drastically reduced poverty level in the regions likewise in the Sub-Sahara Africa through the introduction of technology. They finally concluded that this method is achievable when it is combined with the use of crop rotation pattern so as to maintain the fertility of soil.

Omidire et al. (2015) conducted a study at S and B farm on assessing the impacts of inorganic and organic fertilizers on crop performance under a micro irrigationplastic mulch regime where several in organic fertilizers were mixed with microbe mix and organic fertilizers. In their studies, all these fertilizers were applied to some crops which include cucumber, crops squash and okra in a complete randomized design. Their results showed that the crops produced better yields when inorganic fertilizers were applied than that of organic fertilizers especially when microbes is added to it.

In the same vein, Kyi et al. (2019) investigated the effect of integrated organic and in-organic fertilizers in yield and growth of rice varieties. Two varieties of rice considered are indica rice variety Manawthukha and japonica rice variety Genkitsukushi. In their experiment, they applied manure sequel to the Estimated Mineralizable Nitrogen (EMN) level. However, they measured higher Soil Plant Analysis Development (SPAD) values in Genkitsukushi at all growth period which actually lead to high seed and yield production than chemical fertilizer $\left(\mathrm{CF}_{100}\right)$

In the year 2005 and 2006 (Jahan, et al.) embarked on a study to assess the effect of different cattle manure levels on organic production of squash. Four manure levels were considered as treatments even at the beginning of the year. While in the second year, only the effect of manures were eventually examined. The results revealed that at manure level the fruits and seed yield of squash increased tremendously.

Oyewole et al. (2011) examined the effect of categories of nutrients such as; Poultry Manure (PM), inorganic fertilizer with Poultry Manure on the production of tomato and okra but being planted on the sandy soil only. In their research, types of Nitrogen considered are (0, 150 and 300) $\mathrm{kgNha}^{-1}$ with the use of organic, inorganic and both types of fertilizers as a single manure. Consequently, the outcome revealed that the application of both combination of fertilizers yielded better production other than individual application. They therefore recommended that the combination of $150 \mathrm{~kg}$ PM and $150 \mathrm{~kg}$ inorganic fertilizers $\mathrm{ha}^{-1}$ is the best fertilizers' application especially in the planting of tomato and okra even in sandy soil.

To corroborate the research of Oyewole et al. (2011), Anjanappa et al. (2012) carried out another research on the combination of bio fertilizers, inorganic and organic in the planting of cucumber. The experiment was actually performed in the year 2005 and 2006. Hence, the 
combination of the fertilizers yielded bountiful and great harvest with out-numbered of fruits even in sizes and weights.

In Indonesia, a field experiment was carried out in (2019) by (Akil et al) in order to examine and evaluate different commercial bio fertilizers on Grain yield of hybrid maize under field conditions using Randomized Complete Block Design arrangement with three (3) replications. Their research revealed that leaf Chlorophyll, NPK leaves levels, plant height, Kernel row, ear length, 1000 grains yield and grain yield were influenced by bio fertilizer significantly. Likewise, in order to identify types of fertilizers that can increase the production of Onion in Poland; Stanislaw et al. (2019) compared and contrasted Pelletized plant - based fertilizers which include Ekofert $\mathrm{K}$ and $\mathrm{L}$ with non fertilized control and mineral $\mathrm{N}$ - fertilization. At the end of their experiment, they found out that the fertilizers Ekofert $\mathrm{K}$ and $\mathrm{L}$ increased the production of Onion other than their counterpart.

Therefore, this study compares the effect of different Nitrogen fertilizers on the production of NERICA rice among rice farming systems in Nigeria, using the experiment carried out at the department of plant physiology and crop production in the college of plant science and crop production Federal University of Agriculture Abeokuta (FUNAAB), Ogun State Nigeria. The study also seeks to highlight important factors that could be managed to improve the productivity of rice farms in Nigeria.

\section{Methodology}

In order to ascertain the normality of the data, a formal Normality test was carried out using Kolmogorov Smirnov and Shapiro-Wilk tests. The design used for this research was One-Way ANOVA after the interaction effect between varieties and nitrogen fertilizers has been proved insignificant using factorial design. That is two-ways classification with replicates as shown in table 1 and 2 . Also, a post-hoc was conducted so as to examine which specific groups' means (when compared with each other) are different.

\subsection{Statistical Model for Two-Way Classification with Replicates}

The form of this experiment is such that two factors are involved simultaneously. It also involves combination of levels of the different factors.

The appropriate statistical model is:

$$
\begin{aligned}
\mathrm{y}_{\mathrm{ijk}} & =\mu+\tau_{\mathrm{j}}+\beta_{\mathrm{i}}+(\tau \beta)_{\mathrm{ij}}+\mathrm{e}_{\mathrm{ijk}} \\
\mathrm{i} & =1,2, \ldots, \mathrm{b}, \mathrm{j}=1,2, \ldots, \mathrm{t}, \mathrm{k}=1,2, \ldots, \mathrm{r}
\end{aligned}
$$

where, $\mathrm{y}_{\mathrm{ijk}}$ is the kth observation (yield) arising from level $\mathrm{i}$ of factor $A$ and level $j$ of factor $B$

$\mu$ is the overall mean, $\beta_{i}$ is the $i^{\text {th }}$ effect of factor $A, \tau_{j}$ is the $\mathrm{j}^{\text {th }}$ effect of factor $\mathrm{B},(\tau \beta)_{\mathrm{ij}}$ denotes $\mathrm{ij}$ interaction component with respect to level $i$ of factor $A$ and level $j$ of factor $B$ and $e_{i j k}$ is the random error term.

\subsection{Analysis of Variance (ANOVA)}

The ANOVA is a parametric test for splitting total variation of a set of experimental data into meaningful components that measures different variation from different sources.

\subsubsection{Assumptions of the Analysis of Variance}

The assumptions of the Analysis of Variance are as follows:

i. $\quad$ Error terms are normally distributed

ii. Independence of Error term

iii. Homogeneity of Error variances

\subsection{Division of Sum of Squares}

The total sum of squares of randomized complete block design can be divided into three components, the total variation due to treatment, blocking and error components.

Let $\mathrm{y}_{\mathrm{i} .}=$ total observations taken under block $\mathrm{i}$.

$\mathrm{y}_{\mathrm{.j}}=$ all observations taken under treatment $\mathrm{j}$,

$\mathrm{y}_{\mathrm{N} .}=$ all observations and

$\mathrm{N}=$ total number of observations.

Mathematically,

$$
\begin{array}{rl}
\mathrm{Y}_{\mathrm{i} .}=\sum_{j}^{t} y i j & \mathrm{i}=1,2, \ldots, \mathrm{b} \\
\mathrm{Y}_{. \mathrm{j}}=\sum_{i}^{b} y i j & \mathrm{j}=1,2, \ldots, \mathrm{t} \\
\mathrm{Y}_{. .}=\sum_{i}^{b} \sum_{j}^{t} y i j &
\end{array}
$$

Similarly,

$\overline{\mathrm{Y}}_{\mathrm{i} .}=$ mean of the observation taken under block $\mathrm{i}$,

$\bar{Y}_{. j}=$ mean of the observation in treatment $j$ and

$\overline{\mathrm{Y}}_{. .}=$mean of all observation i.e. $\overline{\mathrm{Y}}_{. .}=\overline{\mathrm{Y}}_{\text {.. }} / \mathrm{N}$

The total corrected sum of squares is expressed as:

$$
\begin{gathered}
\sum_{i}^{b} \sum_{j}^{t}(Y i j-\overline{\mathrm{Y}} . .)^{2}=\sum_{i}^{b} \sum_{j}^{t}[(Y i .-\overline{\mathrm{Y}} . .)+(\overline{\mathrm{Y}} . j-\overline{\mathrm{Y}} . .)+ \\
(Y i j-\overline{\mathrm{Y}} i .-\overline{\mathrm{Y}} . j+\overline{\mathrm{Y}} . .)]^{2}
\end{gathered}
$$

By expanding the right hand side of the equation, we have

$$
\begin{array}{r}
\sum_{i}^{b} \sum_{j}^{t}(Y i j-\overline{\mathrm{Y}} . .)^{2}=\mathrm{b} \sum_{j}^{t}(\overline{\mathrm{Y}} i .-\overline{\mathrm{Y}} . .)^{2}+\mathrm{t} \sum_{i}^{b}(\overline{\mathrm{Y}} . j-\overline{\mathrm{Y}} . .)^{2}+ \\
\sum_{i}^{b} \sum_{j}^{t}((Y i j-\overline{\mathrm{Y}} \mathrm{i} .-\overline{\mathrm{Y}} . \mathrm{j}+\overline{\mathrm{Y}} . .))^{2}+ \\
2 \sum_{i}^{b} \sum_{j}^{t}(\overline{\mathrm{Y}} i .-\overline{\mathrm{Y}} . .)(\overline{\mathrm{Y}} . j-\overline{\mathrm{Y}} . .)+2 \sum_{i}^{b} \sum_{j}^{t}(\overline{\mathrm{Y}} . j- \\
\overline{\mathrm{Y}} . .)(Y i j-\overline{\mathrm{Y}} i .-\overline{\mathrm{Y}} . j+\overline{\mathrm{Y}} . .)+2 \sum_{i}^{b} \sum_{j}^{t}(\overline{\mathrm{Y}} i .-\overline{\mathrm{Y}} . .)(Y i j- \\
\overline{\mathrm{Y}} i .-\overline{\mathrm{Y}} . j+\overline{\mathrm{Y}} . .)
\end{array}
$$

Since the cross products are zero, we have:

$$
\begin{gathered}
\sum_{i}^{b} \sum_{j}^{t}(Y i j-\overline{\mathrm{Y}} . .)^{2}=\mathrm{b} \sum_{j}^{t}(\overline{\mathrm{Y}} i .-\overline{\mathrm{Y}} . .)^{2}+\mathrm{t} \sum_{i}^{b}(\overline{\mathrm{Y}} . j-\overline{\mathrm{Y}} . .)^{2}+ \\
\sum_{i}^{b} \sum_{j}^{t}(Y i j-\overline{\mathrm{Y}} \mathrm{i} .-\overline{\mathrm{Y}} . \mathrm{j}+\overline{\mathrm{Y}} . .)^{2}
\end{gathered}
$$

The equation above represents a partition of the total sum of squares. 
Expressing the sum of square symbolically, we have:

$$
\text { SStotal }=\text { SStreatment }+ \text { SSblock }+ \text { SSerror }
$$

\subsection{One Way ANOVA}

Table 1. Analysis of variance (ANOVA) table

\begin{tabular}{ccccc}
\hline $\begin{array}{c}\text { Source of } \\
\text { variation }\end{array}$ & $\begin{array}{c}\text { Degree of } \\
\text { freedom }\end{array}$ & $\begin{array}{c}\text { Sum of } \\
\text { Squares }\end{array}$ & $\begin{array}{c}\text { Mean Sum of } \\
\text { Squares }\end{array}$ & F \\
\hline Treatment & $\mathrm{t}-1$ & Sstreatment & MSStreatment & $\begin{array}{r}\text { Fcal }= \\
\text { MSStrt }\end{array}$ \\
ESSSerror \\
Total & $\mathrm{t}(\mathrm{n}-1)$ & Sserror & MSSerror & \\
\hline
\end{tabular}

This is a parametric test which is only applicable when there is one treatment used, i.e. ANOVA investigates how population means are equal for a quantitative outcome and a single categorical explanatory variable with any number of levels (see Table 1 and 2)

\subsection{Factorial Experiment (Two Ways Classification with Replicates)}

Two Factor Experiments with replications: In order to consider two main factors, Factor A (Variety) and Factor B (Nitrogen fertilizers); we limit our attention to the total number of replication values corresponding to each combination of factors.

In case of a two factor experiments with replications, there will be more than one entry corresponding to a given treatment and a given block and the appropriate table is provided in table 2 .

\subsection{Tukey HSD Post Hoc Test}

Tukey test also known as Tukey's Honest Significant Difference test, is a test based on the studentized range distribution. One of the deficiencies of an ANOVA test is inability to reveal where results are significant in the analysis but only shows the significancy of the overall results. However, to fill this gap, then a Tukey's HSD is necessary. This can easily be run to examine which specific groups' means (compared with each other) are different. This test compares all possible pairs of means

\subsubsection{Assumptions of Tukey HSD post-hoc test}

The assumptions of Tukey hsd post-hoc test is highlighted as follows;

i. independency of the observations within and among groups

ii. normality assumptions of the groups for each mean and

iii. equality of variances within-group variance and across the groups associated with each mean in the test (homogeneity of variance).

\section{Analysis and Results}

\subsection{Test of Normality}

Normality test was carried out as seen in table 3 using both Kolmogorov Smirnov and Shapiro-Wilk tests of normality and the results revealed that the random sample actually comes from a normally distributed population.

Table 2. ANOVA table for two way classification with replicates

\begin{tabular}{|c|c|c|c|c|}
\hline $\begin{array}{c}\text { Source } \\
\text { of Variation }\end{array}$ & $\begin{array}{c}\text { Degree } \\
\text { of Freedom }\end{array}$ & Sum of Squares & $\begin{array}{l}\text { Mean Sum } \\
\text { of Squares }\end{array}$ & $\mathrm{F}$ \\
\hline Treatment & $\mathrm{t}-1$ & SStreatment & MSStreatment & $\mathrm{F}_{1}=\frac{\text { MSStreatment }}{\text { MSSerror }}$ \\
\hline Block & b-1 & SSblock & MSSblock & $F_{2}=\frac{\text { MSSblock }}{\text { MSSerror }}$ \\
\hline Interaction & $(\mathrm{t}-1)(\mathrm{b}-1)$ & SSinteraction & MSSinteraction & MSSerror \\
\hline Subtotal & (bt-1) & SSsubtotal & & \\
\hline Error & bt(r-1) & SSerror & MSSerror & \\
\hline Total & btr-1 & SStotal & & \\
\hline
\end{tabular}

Table 3. Tests of Normality

\begin{tabular}{cccccc}
\hline \multicolumn{3}{c}{ Kolmogorov-Smirnov } & & \multicolumn{3}{c}{ Shapiro-Wilk } \\
\hline Statistic & Df & Sig. & Statistic & Df & Sig. \\
\hline 0.102 & 60 & 0.189 & 0.972 & 60 & 0.192 \\
\hline
\end{tabular}

Source: Researchers Commutation (2020) 
Table 4. ANOVA table showing two ways analysis of variance with Interaction

\begin{tabular}{|c|c|c|c|c|c|}
\hline \multicolumn{6}{|c|}{ Tests of Between-Subjects Effects } \\
\hline \multirow[b]{2}{*}{ Source } & \multicolumn{2}{|c|}{ Dependent Variable: } & YIELD OF RICE & \multirow[b]{2}{*}{$\mathrm{F}$} & \multirow[b]{2}{*}{ Sig. } \\
\hline & Type II Sum of Squares & Df & Mean Square & & \\
\hline Corrected Model & $18996803.517^{\mathrm{a}}$ & 19 & 999831.764 & 1.705 & 0.077 \\
\hline Intercept & 487652146.817 & 1 & 487652146.817 & 831.710 & 0.000 \\
\hline VARIETY & 13833960.433 & 4 & 3458490.108 & 5.899 & 0.001 \\
\hline TREATMENT & 724409.517 & 3 & 241469.839 & .412 & 0.745 \\
\hline VARIETY * TREATMENT & 4438433.567 & 12 & 369869.464 & .631 & 0.803 \\
\hline Error & 23452976.667 & 40 & 586324.417 & & \\
\hline Total & 530101927.000 & 60 & & & \\
\hline \multirow[t]{2}{*}{ Corrected Total } & 42449780.183 & 59 & & & \\
\hline & \multicolumn{3}{|c|}{ a. $\mathrm{R}$ Squared $=.448$ (Adjusted R Squared $=.185)$} & & \\
\hline
\end{tabular}

Source: Researchers Commutation (2020)

Table 5. Multiple Comparisons between the varieties of rice.

\begin{tabular}{|c|c|c|c|c|c|c|}
\hline \multirow{2}{*}{$\begin{array}{l}\text { (i) VARIETIES } \\
\text { OF RICE }\end{array}$} & \multirow{2}{*}{$\begin{array}{c}(\mathrm{J}) \\
\text { VARIETIES OF } \\
\text { RICE }\end{array}$} & \multirow{2}{*}{$\begin{array}{c}\text { Mean Difference } \\
\text { (I-J) }\end{array}$} & \multirow{2}{*}{$\begin{array}{l}\text { Std. } \\
\text { Error }\end{array}$} & \multirow[b]{2}{*}{ Sig. } & \multicolumn{2}{|c|}{ 95\% Confidence Interval } \\
\hline & & & & & $\begin{array}{l}\text { Lower } \\
\text { Bound }\end{array}$ & Upper Bound \\
\hline & NERICA L-20 & 245.58 & 294.473 & 0.919 & -584.93 & 1076.09 \\
\hline \multirow[t]{2}{*}{ NERICA L-19 } & NERICA L-41 & -465.50 & 294.473 & 0.516 & -1296.01 & 365.01 \\
\hline & NERICA L-42 & -687.58 & 294.473 & 0.149 & -1518.09 & 142.93 \\
\hline \multirow[t]{2}{*}{ Tukey HSD } & NERICA L-60 & 645.58 & 294.473 & 0.198 & -184.93 & 1476.09 \\
\hline & NERICA L-19 & -245.58 & 294.473 & 0.919 & -1076.09 & 584.93 \\
\hline \multirow[t]{3}{*}{ NERICA L-20 } & NERICA L-41 & -711.08 & 294.473 & 0.127 & -1541.59 & 119.43 \\
\hline & NERICA L-42 & $-933.17^{*}$ & 294.473 & 0.020 & -1763.68 & -102.66 \\
\hline & NERICA L-60 & 400.00 & 294.473 & 0.656 & -430.51 & 1230.51 \\
\hline \multirow[t]{5}{*}{ NERICA L-41 } & NERICA L-19 & 465.50 & 294.473 & 0.516 & -365.01 & 1296.01 \\
\hline & NERICA L-20 & 711.08 & 294.473 & 0.127 & -119.43 & 1541.59 \\
\hline & NERICA L-42 & -222.08 & 294.473 & 0.942 & -1052.59 & 608.43 \\
\hline & NERICA L-60 & $1111.08^{*}$ & 294.473 & 0.004 & 280.57 & 1941.59 \\
\hline & NERICA L-19 & 687.58 & 294.473 & 0.149 & -142.93 & 1518.09 \\
\hline \multirow[t]{4}{*}{ NERICA L-42 } & NERICA L-20 & $933.17^{*}$ & 294.473 & 0.020 & 102.66 & 1763.68 \\
\hline & NERICA L-41 & 222.08 & 294.473 & 0.942 & -608.43 & 1052.59 \\
\hline & NERICA L-60 & $1333.17^{*}$ & 294.473 & 0.000 & 502.66 & 2163.68 \\
\hline & NERICA L-19 & -645.58 & 294.473 & 0.198 & -1476.09 & 184.93 \\
\hline \multirow[t]{3}{*}{ NERICA L-60 } & NERICA L-20 & -400.00 & 294.473 & 0.656 & -1230.51 & 430.51 \\
\hline & NERICA L-41 & $-1111.08^{*}$ & 294.473 & 0.004 & -1941.59 & -280.57 \\
\hline & NERICA L-42 & $-1333.17^{*}$ & 294.473 & 0.000 & -2163.68 & -502.66 \\
\hline
\end{tabular}

Source: Researchers Commutation (2020)

\subsection{Test of Homogeneity of Variance}

The test of Homogeneity of variance revealed that error variances of the dependent variable are the same since p-value $(=0.312)>\alpha(=0.05)$ as it is shown in table 4 .

Comment: For Variety (block) from Table 4, since p-value $(=0.001)<\alpha(=0.05)$, at the given significance level, $\alpha=0.05$. There is a significant effect of variety of rice on the measured yield of Rice in tons.

For nitrogen fertilizer (treatment): since p-value $(=0.745)>\alpha(=0.05)$, therefore, there is no significant effect of levels of fertilizer on the measured yield of Rice in tons. Also, for interaction effect; p-value $(=0.803)>\alpha$ $(=0.05)$, there is no significant interaction effects between nitrogen fertilizers and rice varieties whereas, for variety, there is significant difference in the yield of rice. In the 
same vein, for nitrogen fertilizer there is no significant difference in the effects of nitrogen fertilizers on the yield of rice i.e. the fertilizers have equal effects on the yields of rice in tons.

\subsection{Tukey HSD Post-Hoc Test}

Comment: From the post hoc test Table 5, it was observed that there is no significant difference in the yield of NERICA L-19 and the yields of other rice varieties since their p-values are greater than 0.05 level of significance. It was also observed that there is no significant difference in the yield of NERICA L-20 and the yields of other rice varieties except NERICA L-42 whose yield differ from that of NERICA L-20. It was also observed that there is no significant difference in the yield of NERICA L-41 and the yields of other rice varieties except NERICA L-60 whose yield differ from that of NERICA L-41 since its p-value is less than 0.05 level of significance.

It was also observed that there is no significant difference in the yield of NERICA L-42 and yields of NERICA L-19 and NERICA L-41, but there exists significant difference in the yield of NERICA L-42 and yields of NERICA L-20 and NERICA L-60.

Lastly, it was also observed that there is no significant difference in the yield of NERICA L-60 and yields of NERICA L-19 and NERICA L-20 but, there exists significant difference in the yield of NERICA L-60 and yields of NERICA L-41 and NERICA L-42 at 0.05 level of significance.

From figure 1 and 2, it is so obvious that there is no significant difference in the yield of NERICA rice varieties planted with different levels of nitrogen fertilizers. It was also observed that optimum yield of rice in tons is obtained from NERICA L-42 while NERICA L-60 produced the minimum yield of NERICA rice in tons regardless of the type of fertilizer applied.

It was revealed that different levels of the nitrogen fertilizer applied did not significantly influenced the tons of NERICA rice produced that is, yield of NERICA rice in tons is independent of kilograms of nitrogen fertilizers applied.

Also, on the average, NERICA (L-19) gave the highest yield when no fertilizer is applied. NERICA (L-20) gave its optimum yield when I20kg of fertilizer was applied. NERICA (L-41) also responded more when $120 \mathrm{~kg}$ of fertilizer is applied. Likewise, both $30 \mathrm{~kg}$ and $120 \mathrm{~kg}$ of fertilizers tend to yield the optimum in NERICA (L-42) breed of rice. NERICA (L-60) also behaves in a similar way like NERICA (L-19) which gave the highest yield when no fertilizer is applied (see Table 4, Figure 1 and 2).

\section{Summary, Conclusions and Recommendations}

\subsection{Summary}

It is quite clear from the results of analysis in the previous section that there are no significant interaction effect between nitrogen fertilizers and rice varieties.

Also there is no significant difference in the mean effect of the nitrogen fertilizers on yield of rice in tons, while there is significant difference in the effect of rice varieties on yield of rice in tons.

\subsection{Conclusion}

The analysis of effect of fertilizers applied at different levels and varieties of rice on its yield shows that there is no significant difference in the effect of fertilizer on yield of rice. It also shows that there are no interaction effects between nitrogen fertilizers and rice varieties. However, a significant difference in the effect of rice varieties on yield of rice in tons was observed.

The confidence interval indicates that the fertilizer level (30kg) gives the optimum mean yield in tons while the fertilizer level $(60 \mathrm{~kg})$ gives the lowest mean yield in tons. Also varietal traits of rice indicates that NERICA L-42 has the optimum yield in tons with the application of nitrogen fertilizers, while NERICA L-60 has minimum yield in tons with the application of nitrogen fertilizers. Also, data used for the analysis are presented in table 6 .

\subsection{Recommendations}

i. From the analysis of data, it can be seen that different levels of the nitrogen fertilizer applied did not significantly influenced the tons of NERICA rice produced because its yield of rice in tons is independent of kilograms of nitrogen fertilizers applied. Hence, NERICA can be recommended for experimenter to be planted in the presence and absence of nitrogen fertilizers.

ii. NERICA L-42 of rice is therefore recommended to experimenters because it has the optimum yield at all levels of applications of nitrogen fertilizers examined and is most productive in all except at $120 \mathrm{~kg}$ where NERICA L-41 is most productive. 


\section{AVERAGE YIELD OF VARIETIES OF NERICA RICE PLANTED WITH DIFFERENT LEVELS OF NITROGEN FERTILIZER}

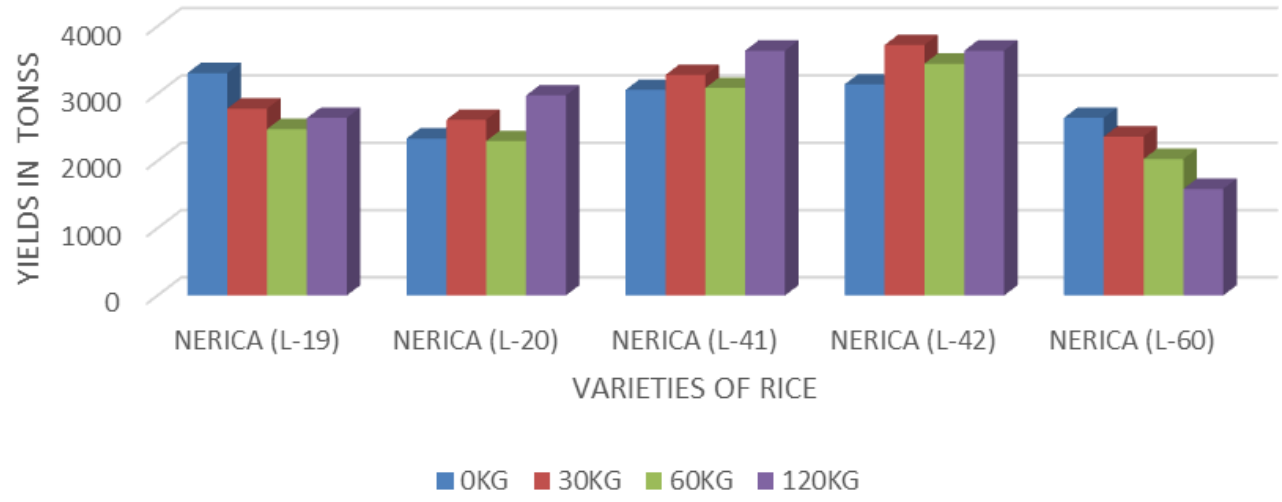

Figure 1. Showing yield of varieties of NERICA rice planted with different levels of nitrogen fertilizers.

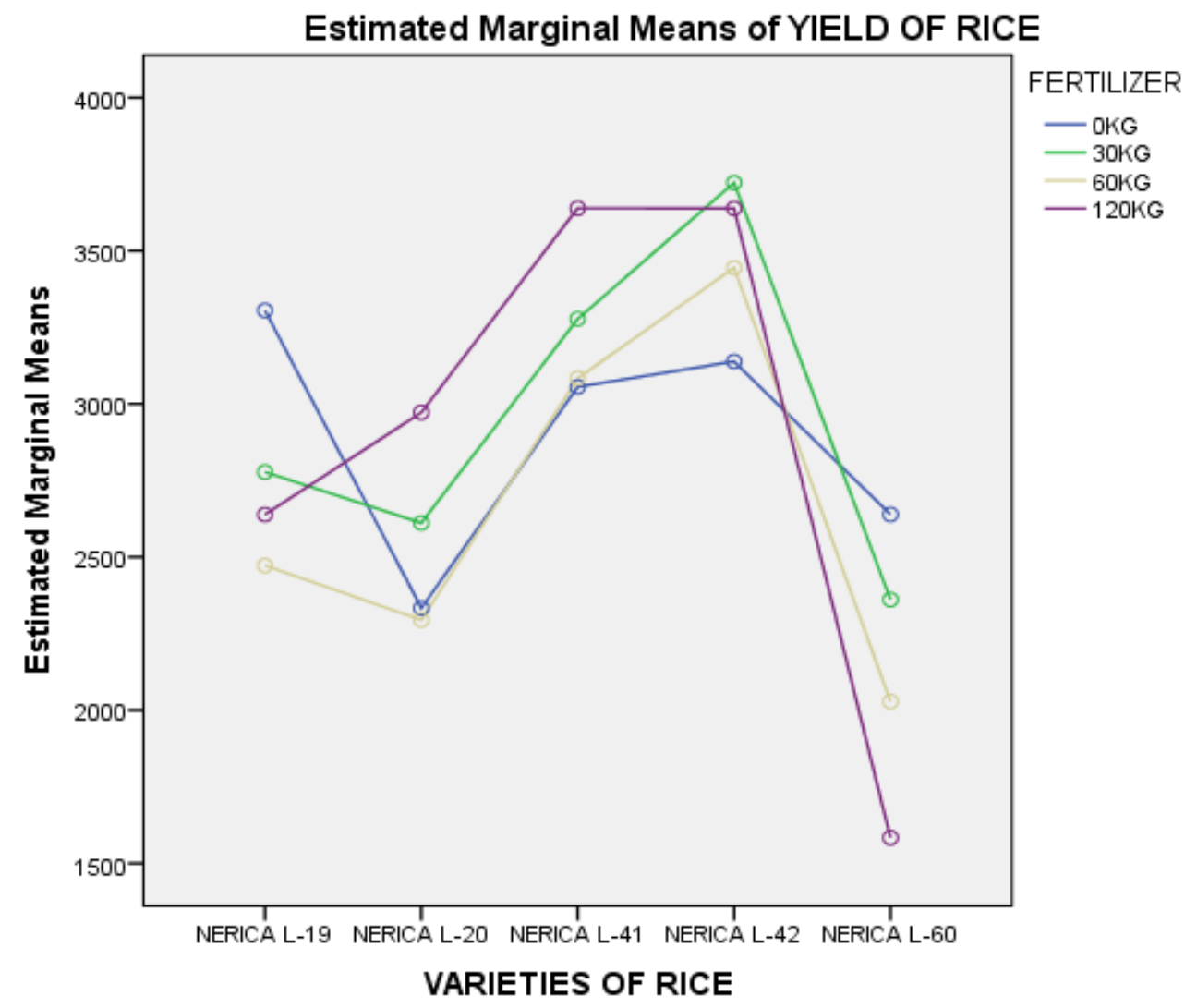

Figure 2. Estimated Marginal Means of Yield of Rice 
Table 6. Data used for the analysis

\begin{tabular}{|c|c|c|c|c|c|}
\hline & \multicolumn{5}{|c|}{ Treatment } \\
\hline & & $0 \mathrm{~kg}$ & $30 \mathrm{~kg}$ & $60 \mathrm{~kg}$ & $120 \mathrm{~kg}$ \\
\hline \multirow{15}{*}{ Varieties } & \multirow{3}{*}{$\begin{array}{c}\text { NERICA } \\
\text { L-19 }\end{array}$} & 2750 & 1833 & 2667 & 2916 \\
\hline & & 3333 & 3583 & 2667 & 2333 \\
\hline & & 3833 & 2917 & 2083 & 2667 \\
\hline & \multirow{3}{*}{$\begin{array}{c}\text { NERICA } \\
\text { L-20 }\end{array}$} & 1583 & 3000 & 2500 & 3167 \\
\hline & & 2917 & 2667 & 2917 & 2500 \\
\hline & & 2500 & 2167 & 1467 & 3250 \\
\hline & \multirow{3}{*}{$\begin{array}{c}\text { NERICA } \\
\text { L-41 }\end{array}$} & 2750 & 2667 & 2917 & 3750 \\
\hline & & 3667 & 4083 & 3917 & 2417 \\
\hline & & 2750 & 3083 & 2417 & 4750 \\
\hline & \multirow{3}{*}{$\begin{array}{c}\text { NERICA } \\
\text { L-42 }\end{array}$} & 2583 & 2750 & 4250 & 4250 \\
\hline & & 3750 & 4750 & 3417 & 4333 \\
\hline & & 3083 & 3667 & 2667 & 2333 \\
\hline & \multirow{3}{*}{$\begin{array}{c}\text { NERICA } \\
\text { L-60 }\end{array}$} & 2250 & 1583 & 2000 & 1917 \\
\hline & & 3000 & 4250 & 2417 & 1417 \\
\hline & & 2667 & 1250 & 1667 & 1417 \\
\hline
\end{tabular}

Source: COPLANT, FUNAAB, (2016).

\section{Declarations}

All authors contributed immensely in one way or the other for the success of the paper.

\section{Competing Interest Statement}

The authors hereby declare that there is no conflict of interest.

\section{Acknowledgements}

We express our profound gratitude the Head of the department of plant physiology and crop production, college of plant science and crop production Federal University of Agriculture Abeokuta (FUNAAB), Ogun State Nigeria for his support during the collection of the data used in the study for analysis. We also acknowledge the financial assistance from the Covenant University Centre for Research and Innovation Development (CUCRID).

\section{REFERENCES}

[1] Akil, M., Purwani, J. Tabri, F. and Azrai, M. (2019). Evaluation of various commercially available Biofertilizers on Grain yield of Hybrid Maize under field conditions at South Silawesi, Indonesia. Universal Journal of Agricultural Research. 7(2). 112 - 116. Doi: 10.13189/ujar.2019.070203.

[2] Akintayo, I., Aliou, D., Soul-kifouly, G. M. and Marco, W. The NERICA Success Story. Development, Achievements and lesson Learned. The Africa Rice Center Cotonou Benin, 2010.

[3] Anjanappa. A., Venkatesh, J. and Kumara, B. S. Influence of organic, Inorganic and Biofertilizers on flowering, Yield and Yield Attributes of Cucumber (CV. Hassan local) in open field condition. Karnataka Journal Agricultural Science,25,4 (2012), 493-49.

[4] Balasubramannian. V., Sie, M., Hijmans, R. J. and Otsuka, K. Increasing Rice production in Sub-Saharan Africa: Challenges and Opportunities. Advances in Agronomy, 94(2007),55-133.

[5] Jahan, M., Koocheki, A., Nassiri, M. and Dehghanipur, F. American-Eurasian. Journal of Agriculture and Environmental Science,6, (2008), 748- 752.

[6] Kamara, A. Y., Ekeleme, F. Omoigui, L. O. and Chikoye, D. Influence of nitrogen fertilization on yield and yield components of rain-fed lowland NERICA rice in the northern Guinea Savanna of Nigeria. African Journal of Agricultural Research, 6(13),(2011). pp. 3092 - 3097.

[7] Kejiro, O. and Sserunkuuma, K. (2007) Assessing the impact of NERICA on income and poverty in Central and Western Uganda. Journal of Agricultural Economics, 38,3:327 - 337.

[8] Kyi, M., Seinn, M. M., Aung, Z. H., Yoshiori, K. and Takeo, Y. (2019). Effects of integrated organic and inorganic fertilizers on yield and growth parameters of rice varieties. Journal of Rice Science. 26(5): 309 - 318.

[9] Oikeh, S. O., Nwilene, F., Ditatta, S., Osmame, O., Touré, A. and Okeleye, K. A. Responses of Upland NERICA Rice to Nigeria and Phosphorus in Forest Agroecosystems. Agronomy Journal, 100, 3(2008)735 - 741.

[10] Okello, S., Massa O. K., Kisho, M., Atsushi, M. Yusuke, H. Shunsuke, M., Tatsushi, T., Godfre, A. and Michiko, T. NERICA Cultivation and its Yield Determinants. The case of Upland Rice Farmers in Namulonge Central Uganda, Journal of Agricultural Science published by (Canadian Center of Science and Education,4,6 (2012).

[11] Olaleye, A. O. and Ogunkunle, A. O. Management of Two Potentially Iron toxic benchmark Wetlands Using Integrated approach for rice production in Nigeria. Journal of Agronomy and Crop Science, 194, 3(2008), 233 - 243.

[12] Omidire, N. S., Shange, R. Khan, V., Bean, R. and Bean, J. (2015). Assessing the impacts of inorganic and Organic Fertilizers on crop performance under a micro irrigation plastic mulch regime. Professional Agricultural workers Journal, 3(1,6).

[13] Omonijo, D. O., Obiorah, B. C., Uche, O. O. C., Anyaegbunam, M. C. Shaibu, A. O and Ogunwa, C. E. (2017). Exploring Social Paradigm in the Study of Insecurity in Contemporary Nigeria. The Journal of Social Sciences 
Research, 3(7): 59-76,

[14] Omonijo, D. O., Uwajeh, P. \& Anyaegbunam, M. C. (2019). Exploring The Traditional and Attitudinal Factors Challenging The Attainment of Sustainable Development in Nigeria. The 34thInternational Business Information Management Conference (IBIMA) Seville, Spain, between $13^{\text {th }}$ and $14^{\text {th }}$ of November 2019

[15] Omonijo, D. O., Anyaegbunam, M. C., Obiorah, C. B., Nwagbo, S., Olowooere, E. I. and Caleb, C. A., (2019). Examining the Social Problem of Kidnapping as a Reaction Against Injustice in Nigeria. Academic Journal of Interdisciplinary Studies,8(2): 158-168. Doi: 10.2478/ajis-2019-0055

[16] Oyewole, C. I., Amhakhian, S. O. and Saliu, O. J. Response of Tomato (Lycopersicon Asculentum) and Okra
(Abelmoschus Esculentus) (L). Monench to Rates of NPK Nutrients Applied as minerals, Poultry Manure and oil palm Residue in the Guinea Savanna Agro - Ecological Zone in Nigeria. Journal of International Scientific Publications Agriculture and Food. (2011), Volume 12.

[17] Rodenburg, J. A., Diagne, S., Oikeh, K., Futakuchi, P. M., Kormawa, M., Semon, I., Akintayo, B., Cissé, L., Narteh, F., Nwilene, S., Diatta, Y., Sere, M., Ndjionjop, N. and Keya, S. O. Achievement and Impact of NERICA on Sustainable rice production in Sub-Saharan Africa Int. Rice Comm. Newsletter 55. (2006),45 -58.

[18] Stanislaw, K., Irena, B. and J O' zef, B. (2019). New pelleted plant - Based fertilizers for Sustainable Onion production. Universal Journal of Agricultural Research 7(6): 210 - 220, 2019. Dio: 10.13189/ujar.2019.070603. 